Review Article

\section{Video-assisted thoracic surgery in advanced non-small cell lung cancer treatment}

\author{
Anil Gokce ${ }^{1 *}$ and Celal Bugra Sezen² \\ ${ }^{1}$ Thoracic Surgeon, University of Health Sciences, Ankara City Hospital, Department of Thoracic \\ Surgery, Bilkent, Ankara, Turkey \\ ${ }^{2}$ Associate Professor, University of Health Sciences, Yedikule Chest Diseases and Thoracic Surgery \\ Training and Research Hospital, Department of Thoracic Surgery, Istanbul, Turkey
}

\section{Abstract}

Non-small cell lung cancer is one of the leading causes of cancer-related mortality worldwide. Despite recent advances in adjuvant treatments, surgical resection is basis of treatment. With the development of minimally invasive surgery in thoracic surgery, surgeons work on minimally invasive surgery for advanced stages of lung cancer, previously considered non-operable at all or previously considered non-operable with minimally invasive surgery approach.

Minimally invasive surgical techniques which are routinely used in the surgical treatment of early-stage lung cancer have started to be treated in more complicated and advanced stages of lung cancer. Bilateral anatomic resections, operations after neoadjuvant chemotherapy, bronchial sleeve lobectomies, double sleeve lobectomies, complementary pneumonectomies, and carinal sleeve resections can be performed by minimally invasive methods. The option of video-assisted surgery should be considered with oncological principles at foreground if patients have acceptable lung and cardiac performance conditions with minimal comorbidities.

This study reviews VATS experience in patients with advanced-stage lung cancer worldwide and discusses potential benefits and limitations of using VATS technology to perform thoracic surgery procedures.

\author{
More Information \\ *Address for Correspondence: Anil Gokce, \\ MD, Thoracic Surgeon, University of Health \\ Sciences, Ankara City Hospital, Department of \\ Thoracic Surgery, Bilkent, Ankara, Turkey, \\ Tel: +90 31255260 00; +90 50525924 15; \\ Email: anil66gokce@hotmail.com \\ Submitted: 05 August 2020 \\ Approved: 13 August 2020 \\ Published: 14 August 2020
}

How to cite this article: Gokce A, Sezen CB. Video-assisted thoracic surgery in advanced non-small cell lung cancer treatment. Arch Surg Clin Res. 2020; 4: 035-038.

DOI: 10.29328/journal.ascr.1001050

Copyright: $\odot 2020$ Gokce A, et al. This is an open access article distributed under the Creative Commons Attribution License, which permits unrestricted use, distribution, and reproduction in any medium, provided the original work is properly cited.

Keywords: Advanced lung cancer; VATS; Minimal invasive surgery

(D) Check for updates

(3) OPEN AcCEss

\section{Introduction}

Video-assisted thoracic surgery (VATS) in anatomical lobectomy for lung cancer was described in 1993 first-time. Since then, many thoracic surgery centers have adopted this technique. Main reason of many centers successfully implement this technique in a short time is short learning curve. [1,2] In prospective, case-control and retrospective studies, it was observed that in non-small cell lung cancer patients, VATS provide same and sometimes better results than open surgery in terms of complete resection, lymph node dissection, locoregional recurrence and early and long term survival [3]. VATS have more advantage than open surgery in early surgical results such as pulmonary and cardiac morbidity, mortality, respiratory function, hospital stay and quality of life $[4,5]$. Also, minimally invasive surgical techniques, which are routinely used in the surgical treatment of early-stage lung cancer have started to treat in complicated and advanced stages of lung cancer [6,7]. Bilateral anatomic resections, operations after neoadjuvant chemotherapy, bronchial sleeve lobectomies, double sleeve lobectomies, complementary pneumonectomies, and carinal sleeve resections may be performed with minimally invasive methods $[8,9]$.

In this study, advanced stage non-small cell lung cancer (NSCLC) patients, which operated with VATS technique were investigated using the PubMed database. In literature, it was evaluated by considering criteria such as tumor size and location, local advanced stage, and invasion into surrounding tissues. In the light of the analysis, this study was planned to guide for thoracic surgeons using the VATS technique in advanced-stage lung cancer.

\section{Vats lung resections}

The first known thoracoscopic procedure was performed by Hans Christian Jacobaeus. In the 1990s, it was mostly used for treatment of pleural biopsy, lung biopsy, empyema, and pneumothorax. However, use of VATS lobectomy in the surgical treatment of lung cancer has appeared in time. The 
first VATS lobectomy was performed by Dr. Ralph Lewis using stapler in 1992. VATS lobectomy was performed by Dr. G. Roviaro with dissection pulmonary artery, pulmonary vein and bronchus separately (hiler dissection) in 1993. Nowadays, number of patients who were operated with VATS method has increased significantly. With increasing use of VATS method over time, it has been seen to have many advantages with proper patient selection [10].

The most important advantages of minimally invasive surgery are better cosmetic results, less pain, earlier mobilization, less drainage time, less postoperative hospital stay and less moribidity than thoracotomy [11,12]. It is considered that the most important reason of less acute and chronic pain is the absence of costal exclusion. In the study of Chen, et al., it was stated that 120 patients with clinical stage II and III-A non-small cell lung cancer underwent lobectomy. Conversion to thoracotomy was $11.7 \%$. Hospital length of stay was shorter in thoracoscopic lobectomy than thoracotom, postoperative complications were similar, 5-year disease-free and overall survival were similar [13]. In the study of Augustin, et al., it was stated that 390 patients were performed with anatomical VATS resections. Extended VATS resections were performed in 29 patients (7.8\%): bilobectomy in 8, bronchoplastic resection in 15 and pneumonectomy in 6. Hospital mortality was not seen and major complications occurred in 3 patients. The median operative time was 217 minutes, the median chest tube duration was 4 days, the median length of hospital stay was 9 days [14]. In the light of these studies, it was seen that VATS method has advantages than thoracotomy in terms of parameters such as pain, length of hospital stay, and complications.

In non-small cell lung cancers, there are various parameters such as tumor size, invasion of adjacent anatomical structures or lymph node involvement are effective in the patient's advanced tumor. Considering the studies in the literature in terms of these features; in the study of Nakano, et al., it was stated that 68 patients had primary lung cancer ( $>5-\mathrm{cm}$ diameter), the patients underwent anatomical pulmonary resection (VATS n: 35, thoracotomy $\mathrm{n}$ : 33). VATS group had less intraoperative bleeding and a shorter length of postoperative hospital stay, there was no significant difference for 1- and 5-year overall survival in both groups. [15] In the study of Hennon, et al., it was reported that 125 patients were evaluated, thoracoscopic lobectomy was completed in 73 patients. Overall survival were 43.7 vs. 22.9 months and disease-free survival were 34.7 vs. 16.7 months in thoracoscopic and open groups. Also, operation time, hospital length of stay, operative blood loss and major complications were similar in both groups [16]. In the study of Gonzalez-Rivas, et al., it was reported that 130 patients were analyzed, 87 patients was early stage and 43 advanced stage. Upper lobectomies (52 vs. 21) and anatomic segmentectomies ( 4 vs. 0 ) were performed in the patient group, conversion to thoracotomy was $1.1 \mathrm{vs.} 6.5 \%$, respectively. Surgical time was longer, and median number of lymph nodes (14vs. 16, $p=0.004$ ) were statistically higher in advanced cases. Median number of nodal stations, hospitalization and rate of complications were similar in both groups. It was stated that uniportal VATS lobectomy for advanced cases of NSCLC was a safe and reliable procedure that provides perioperative outcomes similar to those obtained in early stage tumours operated through this same technique [17].

Depending on the size of tumor, extensive invasion of close anatomical structures, and involvement of lymph node, patient's advanced stage are features that cause operation difficult. However, these features may cause operation almost impossible or hazardous. Therefore, patients may receive induction or adjuvant therapy. In the study of Huang, et al., it was stated that 43 NSCLC patients underwent VATS after neoadjuvant therapy. The patients with stage IIA-IIIB NSCLC were included in this study, 28 patients underwent pulmonary lobectomies, 5 double lobectomies, 5 wedge resections, and 5 total pneumonectomies, 7 patients Hybrid VATS. The 1-, 2, and 3-year overall survival rates were $94 \%$, $79 \%$, and 65\%, respectively. Postoperative complications was $9.5 \%$ and perioperative mortality was $2.4 \%$. [18] In the study of Matsuoka, et al., it was reported that 110 patients were examined, thoracoscopic surgery was performed in 79 patients and thoracotomy in 31. Incidence of postoperative complications were similar in two groups, conversion to thoracotomy was required in 4 patients. Overall 3- and 5-year survival were $58.6 \%$ and $50.3 \%$, respectively, and there was no significant difference in overall survival for both groups [19].

Minimally invasive surgical techniques which are routinely used in surgical treatment of early-stage lung cancer are used in more complicated and advanced stages cases. Bilateral anatomical resections, bronchial sleeve lobectomies, double sleeve lobectomies, complementary pneumonectomies, and even carinal sleeve resections may be performed with minimally invasive methods. In the study of Lyscov, et al, it was stated that six patients underwent uniportal VATS double sleeve and carinal resections. Conversion to thoracotomy was not required. The mean postoperative hospital stay was $10.8 \pm 0.8$ days and postoperative mortality was not seen. It was emphasized that uniportal VATS technique may be a feasible and safe option for complex sleeve resections in advanced stages of lung cancer. [20] In the study of Gao, et al., it was reported that 54 VATS sleeve lobectomy and 94 thoracotomy sleeve lobectomy operations were examined. There was significantly less blood loss (228vs. $246 \mathrm{~mL}$ ), shorter thoracic drainage time (4.6 vs. 6.8 days), postoperative hospital stay (9.2 vs. 11.3 days) in VATS group. However, the recurrencefree survival (50.9\% vs. $48.7 \%)$ and overall survival $(79.5 \%$ vs. $66.7 \%$ ) were not significantly different in two groups. 
And it was emphasized that VATS sleeve lobectomy was a safe and effective procedure associated with better postoperative results and similar oncological results, even for locally advanced non-small cell lung cancer patients with an invasive tumor size larger than $3 \mathrm{~cm}$ or accompanying lymphatic invasion [21].

The advantages of minimally invasive surgery in terms of lung cancer treatment have significance with applying proper oncological principles. In the study of Fan, et al., it was stated that 132 patients with locally advanced NSCLC underwent uniportal VATS (n: 64) or open thoracotomy (n: 68). Hospital of stay and chest tube duration were shorter in uniportal VATS group and rate of complications were higher in open thoracotomy group. Also, the median operative time (157.0 vs. 160.6) and number of lymph nodes (35.5 vs. 32.5) were similar in both groups. In addition, a higher percentage of patients who underwent uniportal VATS resections were proper to receive adjuvant therapy compared to the open group [22]. Oncological effectiveness for lung cancer means compatibility of anatomical resection and lymph node dissection. Improper anatomical dissection causes local and systemic recurrences, incomplete lung cancer staging, omitting occult lymph node metastasis, and depriving adjuvant therapy that should normally be applied (Tables 1,2).

\section{Conclusion}

Nowadays, the tendency towards minimally invasive surgical methods in all surgical branches is quite high. These methods are especially important in terms of patient comfort and quality of life after surgery. Minimally invasive surgical methods may be used safely and with high efficacy in lung cancer surgery where oncological surgical principles are at foreground. Especially in early-stage lung cancer, minimally invasive surgical approach is an almost standard treatment. Through experience gained in the VATS method over time and studies in literatüre, we consider that minimally invasive surgical techniques may be standart surgical treatment of advanced stage lung cancer.

\begin{tabular}{|c|c|c|c|c|c|c|c|c|c|}
\hline References & Year & $\begin{array}{c}\text { Number of } \\
\text { Patients }\end{array}$ & Stage & $\begin{array}{l}\text { Resected Mean Lymph Nodes and } \\
\text { Lymph Nodes Stations }\end{array}$ & $\begin{array}{c}\text { Conversions } \\
\text { to } \\
\text { Thoracotomy } \\
(\%)\end{array}$ & $\begin{array}{c}\text { Mean } \\
\text { Times of } \\
\text { Operation } \\
\text { (minutes) }\end{array}$ & $\begin{array}{c}\text { Times of } \\
\text { Stay in } \\
\text { Hospital } \\
\text { (davs) }\end{array}$ & $\begin{array}{c}\text { Postoperative } \\
30 \text { Days } \\
\text { Morbidity } \\
(\%)\end{array}$ & $\begin{array}{c}\text { Postoperative } \\
30 \text { Days } \\
\text { Mortality } \\
(\%)\end{array}$ \\
\hline Chen $\mathrm{K}$. et al. ${ }^{2}$ & 2017 & 120 & IIA52 IIB24 IIIA44 & 15.6 and 5,5 & 11.7 & 183 & 9.2 & 25 & 0 \\
\hline Augustin F. et al. ${ }^{3}$ & 2016 & $29(370)$ & IA12 IB1 IIA4 IIB6 IIIA6 & $\mathrm{n} / \mathrm{a}$ & 5.1 & 217 & 9 & 17,1 & 0 \\
\hline Nakano T. et al. ${ }^{4}$ & 2015 & 35 & $>5 \mathrm{~cm}, \mathrm{~T} 3$ veya $\mathrm{T} 4$ & n/a & 5,7 & 169 & 11,4 & 31,4 & 0 \\
\hline Hennon M. et al. ${ }^{5}$ & 2011 & 95 & I 38 II 33 III 16 IV 4 (6th edition) & $\mathrm{n} / \mathrm{a}$ & 23 & 231 & 5 & 38,9 & 1,05 \\
\hline $\begin{array}{l}\text { Gonzalez-Rivas D. } \\
\text { et al. } 6\end{array}$ & 2014 & $43(130)$ & $>5 \mathrm{~cm}, \mathrm{~T} 3$ veya $\mathrm{T} 4$ & $\begin{array}{c}\text { Lymph Nodes: } 16 \\
\text { Lymph Nodes Stations: } 5\end{array}$ & 6.5 & 183.2 & 3 & 14 & 0 \\
\hline Huang J. et al. ${ }^{7}$ & 2013 & $42(43)$ & II3 IIB2 IIIA27 IIIB11 & 16.88 & 7 & 160.48 & 5.45 & 9.5 & 2,3 \\
\hline Matsuoka K. et al. ${ }^{8}$ & 2018 & 79 & $\mathrm{n} / \mathrm{a}$ & n/a & 5 & $\mathrm{n} / \mathrm{a}$ & 9,3 & 13.6 & 1,8 \\
\hline Gao HJ. et al. ${ }^{10}$ & 2019 & 54 & IA-B23 IIA-B19 IIIA12 & 21,3 and 5,5 & 5,6 & 300 & 9.2 & 20,5 & 1,8 \\
\hline Fan J. et al. "I & 2016 & 64 & IB10 IIA14 IIB21 IIIA18 IV1 & 35.5 & 3.1 & 157 & 6,1 & 31,4 & 0 \\
\hline
\end{tabular}

Table 1: Short Term Results of Studies with VATS Technique in Advanced Lung Cancer.

\begin{tabular}{|c|c|c|c|c|c|c|}
\hline References & Year & $\begin{array}{l}\text { Number } \\
\text { of Patients }\end{array}$ & Stage & $\begin{array}{l}\text { Median Follow- } \\
\text { up Time } \\
\text { (months) }\end{array}$ & $\begin{array}{l}\text { Survival } \\
\text { Times }\end{array}$ & $\begin{array}{l}\text { Overall Survival } \\
\text { (\% or months) }\end{array}$ \\
\hline Chen $\mathrm{K}$. et al. ${ }^{2}$ & 2017 & 120 & IIA52 IIB24 IIIA44 & 45 & 5-year & $55 \%$ \\
\hline Nakano T. et al. ${ }^{4}$ & 2015 & 35 & $>5 \mathrm{~cm}, \mathrm{~T} 3$ veya $\mathrm{T} 4$ & 44 & $\begin{array}{l}\text { 1-year } \\
5 \text {-year }\end{array}$ & $\begin{array}{l}91.3 \% \\
39.3 \%\end{array}$ \\
\hline Hennon M. et al. ${ }^{5}$ & 2011 & 95 & I 38 II 33 III 16 IV 4 (6th edition) & 36 & 3-year & 43.7 months \\
\hline Gonzalez-Rivas D. et al. ${ }^{6}$ & 2014 & $43(130)$ & $>5 \mathrm{~cm}, \mathrm{~T} 3$ veya $\mathrm{T} 4$ & 30 & 2.5 -year & $74 \%$ \\
\hline Huang J. et al. ${ }^{7}$ & 2013 & $42(43)$ & II3 IIB2 IIIA27 IIIB11 & 68 & $\begin{array}{l}\text { 1-year } \\
\text { 2-year } \\
\text { 3-year }\end{array}$ & $\begin{array}{l}94 \% \\
79 \% \\
65 \%\end{array}$ \\
\hline Matsuoka K. et al. ${ }^{8}$ & 2018 & 79 & $\mathrm{n} / \mathrm{a}$ & 34,2 & $\begin{array}{l}\text { 1-year } \\
\text { 3-year }\end{array}$ & $\begin{array}{l}58.6 \% \\
50.3 \%\end{array}$ \\
\hline Gao HJ. et al. ${ }^{10}$ & 2019 & 54 & IA-B23 IIA-B19 IIIA12 & 42,3 & 2-year & $79.5 \%$ \\
\hline
\end{tabular}




\section{References}

1. Mazzella A, Olland A, Falcoz PE, Renaud S, Santelmo N, et al. Videoassisted thoracoscopic lobectomy: which is the learning curve of an experienced consultant? J Thorac Dis. 2016; 8: 2444-2453. PubMed: https://www.ncbi.nlm.nih.gov/pmc/articles/PMC5059302/

2. Yao F, Wang J, Yao J, Hang F, Cao S, et al. Video-assisted thoracic surgical lobectomy for lung cancer: description of a learning curve. J Laparoendosc Adv Surg Tech A. 2017; 27: 696-703.

PubMed: https://www.ncbi.nlm.nih.gov/pmc/articles/pmc7021397/

3. Berfield KS, Farjah F, Mulligan MS. Video-assisted thoracoscopic lobectomy for lung cancer. Ann Thorac Surg. 2019; 107: 603-609. PubMed: https://pubmed.ncbi.nlm.nih.gov/30278164/

4. Mun M, Nakao M, Matsuura Y, Ichinose J, Nakagawa K, et al. Videoassisted thoracoscopic surgery lobectomy for non-small cell lung cancer. Gen Thorac Cardiovasc Surg. 2018; 66: 626-631.

PubMed: https://pubmed.ncbi.nlm.nih.gov/30062622/

5. Wang Z, Pang L, Tang J, Cheng J, Chen N, et al. Video-assisted thoracoscopic surgery versus muscle-sparing thoracotomy for nonsmall cell lung cancer: a systematic review and meta-analysis. BMC Surg. 2019; 19: 144.

PubMed: https://www.ncbi.nlm.nih.gov/pmc/articles/PMC6794906/

6. Bendixen M, Jørgensen OD, Kronborg C, Andersen C, Licht PB. Postoperative pain and quality of life after lobectomy via videoassisted thoracoscopic surgery or anterolateral thoracotomy for early stage lung cancer: a randomised controlled trial. Lancet Oncol. 2016; 17: 836-844.

PubMed: https://pubmed.ncbi.nlm.nih.gov/27160473/

7. Oda R, Okuda K, Osaga S, Watanabe T, Sakane T, et al. Long-term outcomes of video-assisted thoracoscopic surgery lobectomy vs. thoracotomy lobectomy for stage IA non-small cell lung cancer. Surg Today 2019; 49: 369-377.

PubMed: https://pubmed.ncbi.nlm.nih.gov/30511319/

8. Gonzalez-Rivas D, Yang Y, Stupnik T, Sekhniaidze D, Fernandez $\mathrm{R}$, et al. Uniportal video-assisted thoracoscopic bronchovascular, tracheal and carinal sleeve resections. Eur J Cardiothorac Surg. 2016; 49 Suppl 1: i6-16.

PubMed: https://pubmed.ncbi.nlm.nih.gov/26609055/

9. Li J, Wang W, Jiang L, Yin W, Liu J, et al. Video-assisted thoracic surgery resection and reconstruction of carina and trachea for malignant or benign disease in 12 patients: three centers experience in China. Ann Thorac Surg. 2016; 102: 295-303.

PubMed: https://pubmed.ncbi.nlm.nih.gov/27112644/

10. Gonzalez-Rivas D, de la Torre M, Fernandez R, Mosquera VX. Single-port video-assisted thoracoscopic left upper lobectomy. Interact Cardiovasc Thorac Surg. 2011; 13: 539-541.

11. Sezen $\mathrm{CB}$, Kocatürk $\mathrm{Cl}$. Videothoracoscopic lobectomy training in non-small cell lung cancer. Turk J Thorac Cardiovasc Surg. 2019; 27 : 199-205.

PubMed: https://www.ncbi.nlm.nih.gov/pmc/articles/pmc7021397/
12. Sezen CB, Bilen S, Kalafat CE, Cansever L, Sonmezoglu $Y$, et al. Unexpected conversion to thoracotomy during thoracoscopic lobectomy: a single-center analysis. Gen Thorac Cardiovasc Surg. 2019; 67: 969-975

PubMed: https://pubmed.ncbi.nlm.nih.gov/31004316/

13. Chen K, Wang X, Yang F, Li J, Jiang G, et al. Propensity-matched comparison of video-assisted thoracoscopic with thoracotomy lobectomy for locally advanced non-small cell lung cancer. J Thorac Cardiovasc Surg. 2017; 153: 967-976.

PubMed: https://pubmed.ncbi.nlm.nih.gov/28088426/

14. Augustin F, Maier H, Lucciarini P, Bodner J, Klotzner S, Schmid T. Extended minimally invasive lung resections: VATS bilobectomy, bronchoplasty, and pneumonectomy. Langenbecks Arch Surg. 2016; 401: 341-348.

15. Nakano T, Endo S, Endo T, Otani S, Tsubochi H, et al. Surgical Outcome of Video-Assisted Thoracoscopic Surgery vs. Thoracotomy for Primary Lung Cancer $>5 \mathrm{~cm}$ in diameter. Ann Thorac Cardiovasc Surg. 2015; 21: 428-434.

PubMed: https://www.ncbi.nlm.nih.gov/pmc/articles/PMC4904850/

16. Hennon M, Sahai RK, Yendamuri S, Tan W, Demmy TL, et al. Safety of thoracoscopic lobectomy in locally advanced lung cancer. Ann Surg Oncol. 2011; 18: 3732-3736.

17. Gonzalez-Rivas D, Fieira E, Delgado M, Mendez L, Fernandez R, et al. Is uniportal thoracoscopic surgery a feasible approach for advanced stages of non-small cell lung cancer? J Thorac Dis. 2014; 6: 641-648.

PubMed: https://pubmed.ncbi.nlm.nih.gov/24976985/

18. Huang J, Xu X, Chen H, Yin W, Shao W, et al. Feasibility of complete video-assisted thoracoscopic surgery following neoadjuvant therapy for locally advanced non-small cell lung cancer. J Thorac Dis. 2013; 5 Suppl 3: S267-273.

PubMed: https://www.ncbi.nlm.nih.gov/pmc/articles/PMC3771588/

19. Matsuoka K, Yamada T, Matsuoka T, Nagai S, Ueda M, et al. Video-assisted thoracoscopic surgery for lung cancer after induction therapy. Asian Cardiovasc Thorac Ann. 2018; 26: 608-614. PubMed: https://pubmed.ncbi.nlm.nih.gov/30249109/

20. Lyscov A, Obukhova T, Ryabova V, Sekhniaidze D, Zuiev V, et al. Double-sleeve and carinal resections using the uniportal VATS technique: a single centre experience. J Thorac Dis. 2016; 8(Suppl 3): S235-241.

PubMed: https://www.ncbi.nlm.nih.gov/pmc/articles/PMC4783727/

21. Gao HJ, Jiang ZH, Gong L, Ma K, Ren P, et al. Video-Assisted vs Thoracotomy Sleeve Lobectomy for Lung Cancer: A Propensity Matched Analysis. Ann Thorac Surg. 2019; 108: 1072-1079. PubMed: https://pubmed.ncbi.nlm.nih.gov/31163131/

22. Fan J, Yao J, Wang Q, Chang Z. Safety and feasibility of uniportal video-assisted thoracoscopic surgery for locally advanced non-small cell lung cancer. J Thorac Dis. 2016; 8: 3543-3550.

PubMed: https://pubmed.ncbi.nlm.nih.gov/28149548/ 